\title{
Application of ICT resources in teaching in Bulgarian schools
}

\author{
ELENA PAUNOVA-HUBENOVA, VALENTINA TERZIEVA, KATIA TODOROVA \\ Institute of Information and Communication Technologies \\ Bulgarian Academy of Sciences \\ Acad. G. Bonchev St., Block 2, 1113 - Sofia \\ BULGARIA
}

\begin{abstract}
New technologies provide many benefits for almost every aspect of human life. They add more opportunities for education, such as innovative teaching approaches, distant learning, easier personalization of resources, access to educational materials on the Internet, etc. To explore different aspects of ICT implementation in the educational process in Bulgarian schools, authors create and disseminate four questionnaires for teachers and students from different educational stages all over the country. The considerable number of respondents for each survey reveals relatively adequately the real situation in schools. First, the paper examines many contemporary technology-based tools and e-resources that contribute to innovative teaching methods. Second, the authors reveal the survey findings concerning the frequency of using ICT in several classroom activities (presenting new knowledge, practicing in class, summarizing, and group projects). The paper compares outcomes both from teachers' and students' questionnaires according to the educational stage. The authors also look at the usefulness and the usage frequency of ICT resources as additional resources, stimulus or reward, an alternative form of education, and for achieving specific goals.
\end{abstract}

Key-Words: e-resources, innovative technologies, learning activities, survey, teaching ICT in school stages Received: December 5, 2019. Revised: May 12, 2020. Accepted: May 31, 2020. Published: June 10, 2020

\section{Introduction}

Now in the 21-st century, it is well established that the use of information and communication technologies (ICT) can improve students' attitudes towards learning and their knowledge acquisition [1], [2], [3]. Many educational researchers around the globe are continually looking for and developing new technological solutions, thus offering powerful, innovative technology tools that help to meet a variety of teaching objectives and students' needs [4]. Conventional textbooks are starting to be replaced by various e-learning content and open educational resources [5]. Nowadays, laptops, tablets, or smartphones with appropriate applications are already used instead of traditional textbooks and notebooks [5], [6]. Distance and personalized learning [7] often provide tailored training guidance following students' educational strengths and weaknesses, as well as their preferences and goals.

Recently, computer literacy has become mandatory in almost all areas of society, hence the education has to prepare students for the contemporary world that is widely dominated by ICT. Getting acquainted with new demands requires starting from school education, where the role of classroom equipment is a crucial factor for innovative teaching [2]. In this aspect, the education sector as a whole is still lagging. As a result, there is a discrepancy between traditional teaching-learning practices and the need for building new skills that meet the requirements of today's technological society.

\section{Related work}

A wide-ranging International Survey on ICT in Education [8] covering teachers and students from the European Union (EU) countries provides a detailed picture of the use of ICT in schools. It examines many parameters related to the availability of ICT equipment and its use. Some countries show a trend of the increasing number of interactive whiteboards (IWB), laptops, projectors, and tablets in most classrooms. The findings, however, reveal that in the EU exist major disparities between different countries and schools both in the availability and use of ICT equipment. For the majority of students in the $\mathrm{EU}$, their teachers never or seldom give them homework online or assess them using ICT. Students report using ICT-based activities between several times a month and never or rarely, which is lower compared to the answers of teachers.

In the EU, on average, at least once a week, more than half of secondary school students use computers and at least a third - IWB, however, there is no correlation between the availability of ICT 
equipment in schools and its frequency of use. Although about $50 \%$ of high school students learn in technology-rich schools, still around $20 \%$ of them have never or rarely used a computer during lessons. The most commonly used resources are digital textbooks and multimedia tools for low and high secondary schools, respectively. However, only about $30 \%$ of students use them once a week or almost every day.

The survey data show that Bulgaria is at one of the last places in terms of the availability of ICT equipment in classrooms and its use in the learning process. However, recently there are significant dynamics in the introduction of technology in teaching practice, which motivate the authors to conduct a national-wide survey. Nowadays, many Bulgarian schools already employ a variety of ICT for educational purposes. Some schools have even specially equipped classrooms for teaching science. The current paper reviews the most common technological tools that transform pedagogical practice and have the potential to improve the learning process by adapting it to the characteristics and expectations of learners. Several forms of technology-assisted teaching approaches are also considered and discussed.

\section{Types of ICT Used in Teaching Process}

Desktop computers are usually one of the most often used in many classroom activities like delivering new knowledge, learning from e-resources, making etests, access to educational materials on the Internet. They give the opportunity a wide variety of eresources to be used. They provide students with more engaging and appealing educational experiences and promote better comprehension of the learning content [2]. For example, phonics e-books help to make connections between text, sounds, and meaning, thus assist learners who are struggling readers (like dyslexics) to increase concentration and attention time. Thus, e-textbooks offer a significant advantage over traditional ones, which is an essential benefit of ICT [3]. Teachers use technologies to prepare different kinds of e-learning resources such as presentations, assignments, e-tests. They also use educational computer video games to present learning matter more intriguingly and enjoyably [9].

However, in recent years, mobile devices are increasingly replacing desktops. Most commonly in schools are used laptops, tablets, smartphones. Less expensive laptops have been designed for educational use with a low-cost operating system and power consumption [10]. Other portable tools for learning are tablets working without a keyboard or mouse and controlled by a touchscreen [1], [3]. They provide creative and individualized options for students and teachers to work with educational apps. Tablets provide almost the same functionality as desktops, making them one of the most appropriate devices for educational purposes. Smartphones have parameters similar to tablets and offer nearly the same capabilities, which makes them a favored tool for learning interactions for many students [11].

Projectors and multimedia systems typically demonstrate learning resources (presentations) or play educational videos. Multimedia systems provide an immersive learning experience in an educational context of delivering and summarizing knowledge. The innovative compact smart laser system for animation projections [12] uses advanced laser diodes, optics, and software that open new possibilities for a more inspiring educational experience. It creates exotic looking and highlycontrast projections of various vector data such as complex charts and graphics. It can also enhance 2-D and 3-D objects with impressive highlights - the socalled 3-D projection mapping, which attracts student attention and facilitates the perception of the learning material. The laser system uses TCP/IP or the specialized communication protocol outlined in [13] to connect to other digital educational services.

Interactive whiteboards designed especially for presenting and interacting with learning content (images, graphs, tables, and quizzes) enable teachers and students to interact with the teaching material through fingers or stylus [3]. IWB emphasizes on shared tasks and students' responses. They are designed for students to do learning activities not individually but with the whole class. Some IWB also offers software for voting systems that are often used in lessons - particularly in the assessment of students by multiple-choice based questions. More elaborative of these devices also can record learning activities during the lesson and playback them later, as details cannot be easily remembered unless recorded in some way.

Some of the most innovative technologies virtual (VR) and augmented (AR) are already employed in teaching sciences. These computergenerated environments can reproduce realistically three-dimensional scenes or artifacts, simulate the physical presence of people or objects, and sensory experiences [14]. Immersion in such an environment simultaneously affects the auditory and visual receptors, enables students to perceive it as a reality where they can move, observe, and interact with available items, thus to study their characteristics 
[15]. VRs assist the learning activities related to examining three-dimensional objects and visualizing interactive learning resources. The opportunity for creating 3D models make learning more realistic and increase students' engagement [16]. AR helps in understanding real world by providing additional information, images, graphics, etc. about studied topics and physical objects. It is very appropriate in the natural sciences and science, technology, engineering, and mathematics (STEM) subjects because it facilitates understanding of dimensions, proportions, and relationships between objects [17]. The use of such technology in training helps to accomplish both aspects of the learning process knowledge transfer (information and skills) and transfer of training (demonstration of abilities in a real environment) [18]. Furthermore, these innovative technologies are highly efficient in teaching people with special educational needs [19].

\section{Methodology}

Results presented in the paper are derived by conducting a widespread survey. The next subsections describe the types of questionnaires spread among teachers and school students as well as the profile of the respondents. The survey's objective is to investigate the different aspects of implementing information technologies in the educational process in Bulgarian schools.

\subsection{About the Survey}

The described survey was held in late 2017 and early 2018 among Bulgarian school students and teachers from all over the country. Four questionnaires were created in the frame of a project "Learning data analytics for ICT resource integration in Bulgarian schools" - one for teachers and the other three for the different stages of school education [20].

Questionnaires address various issues like respondent's profile, conditions, and obstacles to using technology in classrooms, usefulness, and frequency of application of ICTs resources and tools, the new role of teachers, the impact of ICT on the students, and readiness for participating in the creation of e-resources. There are two main types of questions in the survey: 1) with predefined answers (single or multiple choice and Likert scale), and 2) questions with the opportunity for free answers. The presence of free-text comments gives us the possibility to better understand the results from the first type of questions and to analyze them more precisely. The number of questions in the teachers' survey is 21 , while in the students' ones it is only from 12 to 16 . A detailed description of the questionnaires is presented in [21].

The survey was held entirely online, and the participation is voluntarily and anonymously. Questionnaires were spread in all regions of Bulgaria, covering different settlements' sizes (from small towns to the capital city). The surveys were disseminated through the authors' contacts with teachers and school principals. Researchers received support also from regional education management for reaching a broader range of teachers and students. This way of dissemination helped the participation of more respondents from different types of schools, towns, and regions. Thus, their profile is diverse, and their opinions represent more adequately the real situation in Bulgaria.

\subsection{Respondents' Profile}

The total number of respondents (teachers and students) is 9901, and their distribution according to the educational stage is presented in Table 1 . About $21 \%$ of the responded teachers educate students of more than one level, and they are shown separately. Almost half of all respondents are high school students. As respondents fall into different categories, and they are not compared directly, no correlation analysis is required.

Table 1 Distribution of respondents according to educational stage

\begin{tabular}{ccccc}
\hline & Primary & $\begin{array}{c}\text { Low } \\
\text { Secondary }\end{array}$ & $\begin{array}{c}\text { High } \\
\text { Secondary }\end{array}$ & $\begin{array}{c}\text { More than } \\
\text { one stage }\end{array}$ \\
\hline Teachers & 497 & 294 & 508 & 353 \\
& $(5 \%)$ & $(3 \%)$ & $(5 \%)$ & $(4 \%)$ \\
Students & 991 & 2577 & 4681 & - \\
& $(10 \%)$ & $(26 \%)$ & $(47 \%)$ & \\
\hline
\end{tabular}

Teachers' distribution according to the subjects they teach, is presented in Table 2. The largest share teaches IT and Informatics, while the smallest one Engineering. Usually, primary teachers work with a single class for almost all subjects. For this reason, they are not given here. 
Table 2 Distribution of teachers according to the subjects

\begin{tabular}{lcc}
\hline \multicolumn{1}{c}{ Subject } & Number & Percentage \\
\hline Science & 104 & $6.30 \%$ \\
Mathematics & 153 & $9.26 \%$ \\
IT \& Informatics & 222 & $13.44 \%$ \\
Engineering & 55 & $3.33 \%$ \\
Bulgarian language \& literature & 121 & $7.32 \%$ \\
Foreign languages \& literature & 109 & $6.60 \%$ \\
Social studies & 120 & $7.27 \%$ \\
Professional subjects & 149 & $9.02 \%$ \\
Sports and Arts & 83 & $5.02 \%$ \\
\hline
\end{tabular}

\section{Results and Discussion}

This section presents outcomes from the described survey concerning the frequency of using ICT in the classroom activities. The results from the questionnaires of students and teachers are compared according to the educational stage (primary, low and high secondary).

Teachers in almost all subjects implement a variety of technological tools in many activities in classroom teaching, thus meeting the expectations and preferences of digital native students. The majority of respondents use computers (87\%) in the teaching process, and just over $60 \%$ use projectors too. Most often, these tools are used in lessons for presenting and summarizing new knowledge. Almost half of the respondents also employ multimedia, and about one-quarter of educators rely on interactive whiteboards in their teaching activities. The most attractive technology tool for students virtual/augmented reality - is integrated into the practice of only about $4 \%$ of teachers. The following sub-sections describe more detailed the survey findings concerning the usefulness and the usage frequency of ICT resources and tools in most usual classroom activities. Comparison and discussion have been made concerning both teachers' and students' points of view.

\subsection{Frequency of Applying E-Resources in Different Learning Activities}

Frequency of applying e-resources in presenting new knowledge is shown on Fig. 1. Teachers declare to apply information technologies every day almost equally for the three stages $-30 \%$ to $32 \%$. According to primary and low secondary students, teachers use ICTs even more frequently $(38 \%$ and $43 \%$ respectively). Unlike them the senior ones answer with "Very often" only $20 \%$. They choose "Never use" most often $(30 \%)$ of all other groups of respondents (from $6 \%$ to $12 \%$ ).

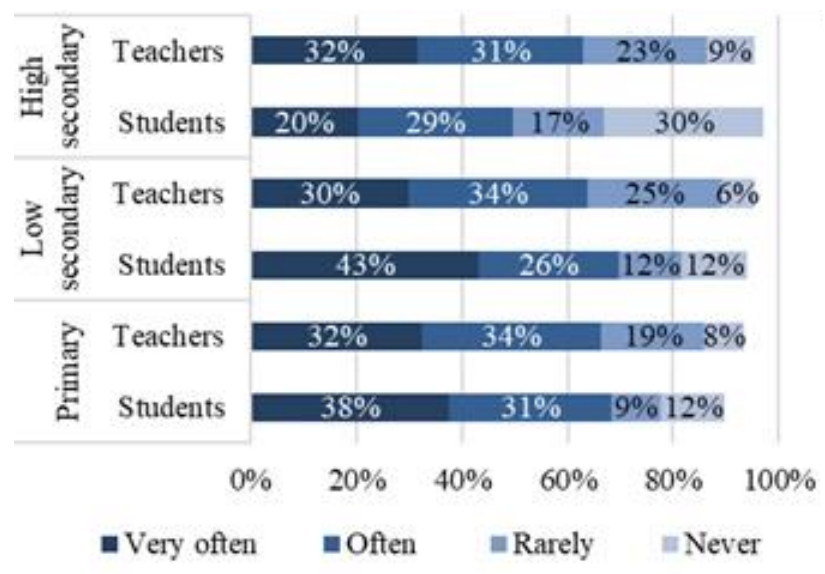

Fig. 1 Frequency of applying e-resources in presenting new knowledge

The disparity between students' and teachers' answers is apparent, and it can have many explanations. The most usual of them are exaggerating or underrating the actual situation, and a not accurate assessment of usage frequency. A possible reason can also be the fact that when students have engaging and pleasant assignments, they would like more such activities, thus assess them as insufficient. Vice versa, if ICT-based teaching activity is difficult and requires more concentration and effort, students rate it as too much. Such a difference in respondents' opinions is also observed in some of the other issues considered bellow. The significance of these differences was checked through a T-test. Only for high and low secondary schools, the disparity in opinions of teachers and students concerning the frequency of applying eresources in presenting new knowledge is statistically significant $(\mathrm{p}<0.0005)$.

Fig. 2 shows the frequency of applying eresources in practicing in class. For the presenting new knowledge, the answers of teachers in the three stages are very close $-24 \%$ to $26 \%$ use ICTs every day. In contrast, high secondary students choose this answer seldom - only $15 \%$, while the option "never use" is $35 \%$. The younger students declare to use new technologies for practicing in class very often from $28 \%$ to $30 \%$, and 14 to $15 \%$ for "never use". All groups of teachers answer with "never use" rarely than their students (from 6\% to 10\%), however the highest difference stays for the high secondary stage.

The disparity in presented data about the opinions of students and teachers for applying e-resources in practicing in class also was checked through a T-test. It is statistically significant $(\mathrm{p}<0.03)$ for both high secondary and primary schools. The obtained results 
for low secondary schools point that $\mathrm{p}=0.2917$, and the differences are not significant.

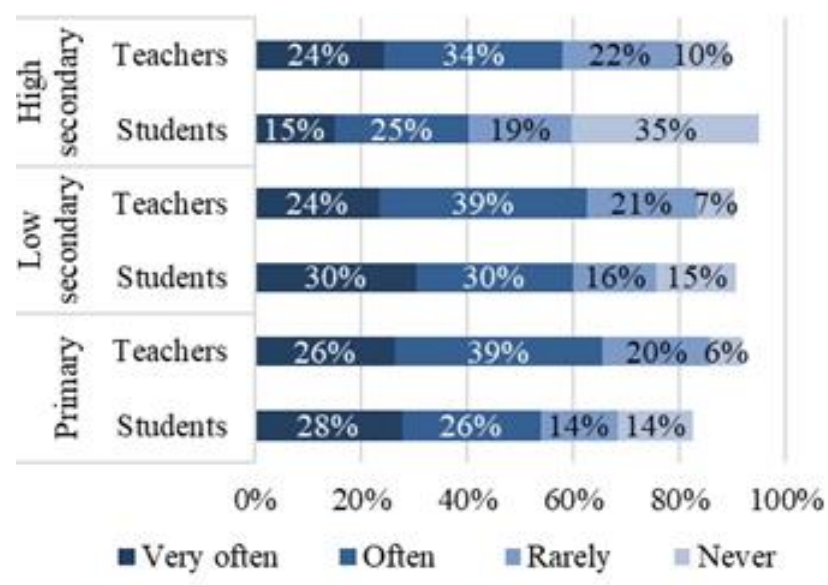

Fig. 2 Frequency of applying e-resources in class practicing

About 20\% of the surveyed teachers use ICTs for summarizing knowledge every day (Table 3). Their opinion is confirmed by low secondary students, but according to high secondary ones, it is about $10 \%$. The reason for this result is that teachers take into account the use of technology in the preparation of the lessons, while students do not appreciate this aspect. Almost half of them answer that their teachers never use technologies for this activity. From 23.20\% to $29.14 \%$ of teachers use new technologies every week for this activity, and from $11.60 \%$ to $7.62 \%$ answer that they never use e-resources in summarizing the knowledge. According to the authors, the youngest pupils cannot give a reliable assessment for this issue, so they are not presented in the table.

Table 3 Frequency of applying e-resources in summarizing the knowledge

\begin{tabular}{|c|c|c|c|c|c|}
\hline & & $\begin{array}{l}\text { Very } \\
\text { often }\end{array}$ & Often & Rarely & Never \\
\hline Primary & Teachers & $21.19 \%$ & $29.14 \%$ & $28.97 \%$ & $7.62 \%$ \\
\hline \multirow{2}{*}{$\begin{array}{l}\text { Low } \\
\text { secondary }\end{array}$} & Students & $21.96 \%$ & $20.64 \%$ & $21.46 \%$ & $22.58 \%$ \\
\hline & Teachers & $19.39 \%$ & $24.52 \%$ & $33.65 \%$ & $9.13 \%$ \\
\hline \multirow{2}{*}{$\begin{array}{l}\text { High } \\
\text { secondary }\end{array}$} & Students & $10.08 \%$ & $16.30 \%$ & $20.81 \%$ & $46.98 \%$ \\
\hline & Teachers & $19.46 \%$ & $23.20 \%$ & $29.90 \%$ & $11.60 \%$ \\
\hline
\end{tabular}

A small part of the teachers includes ICTs for group projects very often (from $9 \%$ for primary to $18 \%$ for high secondary school) or often (respectively $20 \%$ and $27 \%$ ) - see Fig. 3. Usually, teachers use them rarely ( $25 \%$ to $28 \%$ ) or never. The use of technology in project work increases with the age of learners. Students' answers are in line with the statements of their teachers. It makes the impression that a big part of the respondents did not answer this question, especially primary school teachers and students. The main reason is that group projects are not relevant to all subjects and ages. Therefore, it can be assumed that the lack of a response in most cases is equivalent to a "never" answer.

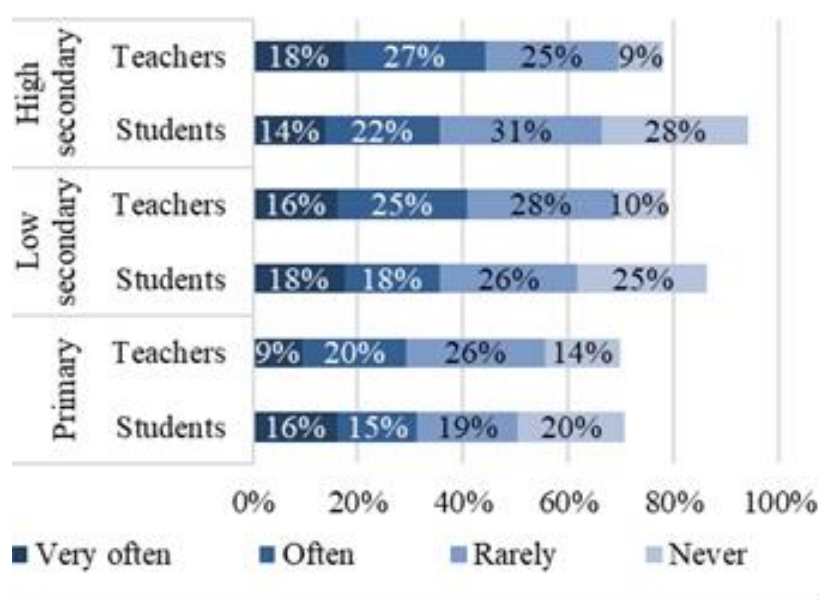

Fig. 3 Frequency of applying e-resources in group projects

Respondents also had to assess the frequency of using new technologies for the following situations: evaluating the students' knowledge, assigning homework, extracurricular activities. Teachers use them very often and often respectively: $19 \%$ to $28 \%$; $22 \%$ to $32 \%$; and $32 \%$ to $39 \%$. In these cases, most of respondents answer with "never use". There are several possible reasons for these results: lack of appropriate e-resources or technical equipment, teachers prefer to use classical resources in these situations.

\subsection{Usefulness and Frequency of Using ICT Resources}

This section presents a comparison of the usefulness (Fig. 4) and the frequency (Fig. 5) of the using ICT resources as additional resources, stimulus or reward, an alternative form of education, and for achieving specific goals. Most teachers prefer to use them as additional resources (67\%), and about 50\% implement them very often or often. A smaller part of responding teachers states that the innovative methods of education are appropriate for achieving specific goals, and $37 \%$ use them at least once a week. 


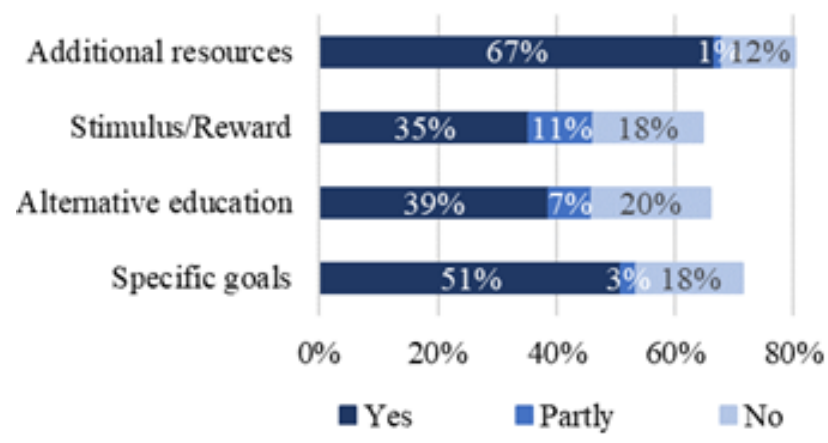

Fig. 4. Usefulness of e-resources in the learning activities

Teachers do not apprise e-resources as appropriate for a stimulus or reward, and an alternative form of education and do not use them often for these purposes. Only 35\% to 39\% of them answer that ICTs are useful, and about a quarter of responded teachers use them for these purposes. Teachers find e-resources useful for most learning activities, but a small part of them apply new technologies every day in the educational process. They still consider as the most significant obstacles insufficient e-resources, lack of technical equipment in schools, or time in the curriculum.

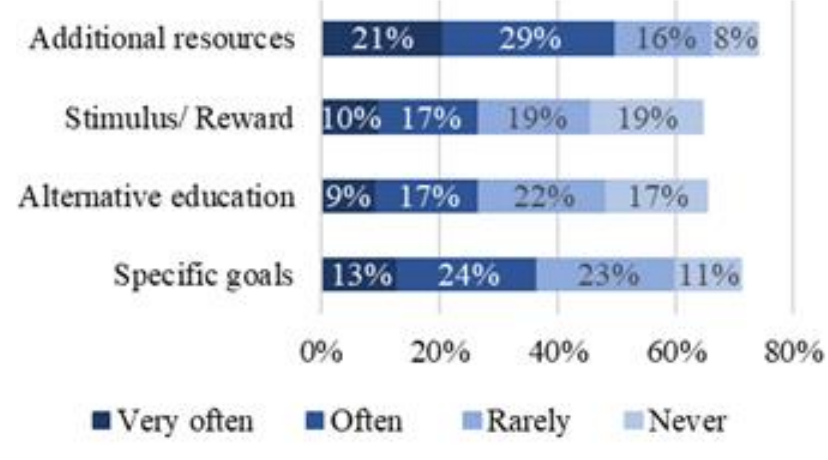

Fig. 5 Frequency of applying e-resources in the learning activities according to teachers

\section{Conclusion}

The multitude of benefits of information technology in the field of education makes them increasingly preferred by teachers. The diversity and accessibility also considerably contribute to their broader implementation in the educational process. Different types of technologies and e-resources are suitable for different situations and goals.

Bulgarian teachers apply e-resources and technological tools most often to present new knowledge or practice it in class. In the comments, teachers outline even more activities: searching for information on the Internet, interdisciplinary work, and teamwork. The surveyed teachers appreciate the impact of ICT on students: "Computer lessons and presentations give a clear idea of the study material.", and "Working with a computer supports learning and develops thinking in children."

The comparison made in the previous section shows that teachers usually rate ICT as useful for a given activity but do not apply them as often. The relatively low frequency of use of ICT resources and tools is a matter of concern. The reasons for these results are related to the current conditions in the Bulgarian schools in the following aspects: availability of technical equipment in the classrooms, access to appropriate e-resources, and the abilities of teachers to work with the new technologies. These conclusions are confirmed by many of the respondents who write comments such as: "We do not have the necessary technical resources in the classrooms.", and also: "We do not always have access to the Internet, and this hinders the learning process. Therefore, we use the safe option - we work with the printed editions in class".

For some of the considered cases of classroom activities, students and teachers make different assessments of the use of ICT resources. Hence, further inquiry and precise statistical analyses are needed to reveal what are the actual reasons.

The presented research could be useful for decision-making authorities in the educational area to see to what extent teachers have used technology tools in the classroom, whether there are appropriate conditions for their implementation in the teaching process, and what is the willingness of learners to benefit from this form of education. Further work will be focused on determining the optimal allocation of ICT-based educational resources to achieve efficient learning. The results will serve stakeholders to decide what amount of e-resources to include in the curriculum and particularly in which activities.

Two years ago, most of the teachers did not trust in new technologies as an alternative form of education. Now, they are struggling with the rapid transition to online learning. Now, they face a situation that ICTs are the only possible alternative to traditional classroom education. On 16'th March 2020, Bulgarian schools close the doors, because of widespread COVID-19, though, the learning process has to go on. Concerning the current situation, an object of future research are issues like "What part of Bulgarian teachers are technically confident and whether additional ICT qualifications are needed for delivering distance education, and what part of the students have received a good quality education during the online learning?" 


\section{Acknowledgment:}

The research is partially supported by the National Scientific Program "Information and Communication Technologies in Science, Education and Security" (ICT in SES) financed by the Ministry of Education and Science.

\section{References:}

[1] Eady M.J., Lockyer L., Tools for Learning: Technology and Teaching Strategies, in Learning to Teach in the Primary School, 2013, pp. 71-92.

[2] Sangrà A., González-Sanmamed M., The Role of Information and Communication Technologies in Improving Teaching and Learning Processes in Primary and Secondary Schools, ALT-J Research in Learning Technology, Vol. 18, No. 3, 2010, pp. 207-220.

[3] Digital Technologies in the Classroom Available at: https://www. cambridgeinternational.org/Images/271191digital-technologies-in-the-classroom.pdf

[4] Luckin R., Bligh B., Manches A., Ainsworth S., Crook C., Noss R., Decoding learning: the proof, promise and potential of digital education, London: NESTA, 2012.

[5] Hilton J., Open Educational Resources and College Textbook Choices: A Review of Research on Efficacy and Perceptions Education Technology Research Development Vol. 64, 2016, pp. 573-590.

[6] Ghavifekr S., Kunjappan T., Ramasamy L., Anthony A. Teaching and Learning with ICT Tools: Issues and Challenges from Teachers' Perceptions, Malaysian Online Journal of Educational Technology, Vol. 4, No. 2, 2016, pp. 38-57.

[7] Pane J.F., Steiner E.D., Baird M.D., Hamilton L.S., Pane J. D., How does Personalized Learning Affect Student Achievement?" Santa Monica CA: RAND Corporation 2017 Available at: $\quad$ https://www.rand.org/pubs/ research_briefs/RB9994.html

[8] The survey of schools: ICT in education Available at: https://ec.europa.eu/digital-singlemarket/en/news/survey-schools-ict-education

[9] Bontchev B., Customizable 3D video Games as Educational Software, in Proc. of Int. Conf. EDULEARN'15, 2015, pp. 6943-6950.

[10] Best Practices for Integrating Chromebooks into Teaching \& Learning, PCM-G, Available at: http://eschoolmedia.com/wp-content/uploads /2016/06/PCMGresource0302.pdf

[11] Information and Communication Technology
(ICT) in Education, Available at: https:// learningportal.iiep.unesco.org/en/issue-briefs/ improve-learning/curriculum-and-materials/ information-and-communication-technology-ict

[12] Ilchev S., Petkov D., Andreev R., Ilcheva Z., Smart Compact Laser System for Animation Projections, Cybernetics and Information Technologies, Vol. 19, No. 3, 2019, pp. 137-153.

[13] Ilchev S., Ilcheva Z., Internet-of-Things Communication Protocol for Low-Cost Devices in Heterogeneous Wireless Networks, in Proceedings of Int. Conf. CompSysTech '17, ACM ICPS, Vol. 1369, 2017, pp. 272-279.

[14] Kavanagh S., Luxton-Reilly A., Wuensche B., Plimmer B., A Systematic Review of Virtual Reality in Education, Themes in Science and Technology Education, Vol. 10, No. 2, 2017, pp. 85-119.

[15] Martín-Gutiérrez J., Mora C.E., Añorbe-Díaz B., González-Marrero, A Virtual Technologies Trends in Education, EURASIA Journal of Mathematic Science and Technology Education, Vol. 13, No. 2, 2017, pp. 469-486.

[16] Fowler C., Virtual Reality and Learning: Where is the Pedagogy? British Journal of Educucational Technology, Vol. 46, 2015, pp. 412-422.

[17] $\mathrm{Hu}-\mathrm{Au}$ E., Lee, J.J. Virtual reality in education: a tool for learning in the experience age, International Journal of Innovation in Education (IJIIE), Vol. 4, No. 4, 2017

[18] Bossard C., Kermarrec G., Buche C., Tisseau J., Transfer of Learning in Virtual Environments: a New Challenge? Virtual Reality, Vol. 12, 2008, pp. 151-161.

[19] Cascales-Martínez, A., Martínez-Segura, M., Pérez-López, D., and Contero, M. Using an Augmented Reality Enhanced Tabletop System to Promote Learning of Mathematics: A Case Study with Students with Special Educational Needs. Eurasia Journal of Mathematics, Science and Technology Education, Vol. 13, No. 2, 2017, pp. 355-380.

[20] Learning data analytics for ICT resource integration in Bulgarian schools, Project, Available: http://hsi.iccs.bas.bg/projects/MPIKT

[21] Terzieva V., Paunova-Hubenova E., Dimitrov S., Boneva Y., ICT in STEM Education in Bulgaria, in Proc. of Int. Conf. on Interactive Collaborative Learning (The Challenges of the Digital Transformation in Education. AISC Vol. 916, eds. M. Auer and T. Tsiatsos (Springer, Cham), 2019, pp. 801-812. 